\title{
Karta potencialnih rastišč poletne gomoljike (Tuber aestivum) kot pri- pomoček pri razvoju gomoljikarstva v Sloveniji
}

\author{
Janez BERGANT ${ }^{1 *}$, Andrej PILTAVER ${ }^{2}$, Nikica OGRIS $^{3}$, Borut VRŠČAJ ${ }^{1}$, Dušan JURC ${ }^{3}$
}

Podzemne glive so skupina gliv, ki celotno življenje preživijo v tleh. Med podzemnimi glivami je gastronomsko in tržno najbolj znanih nekaj vrst podzemnih gliv iz rodu gomoljik (slika 1). Zgodbe o gomoljikah so znane in povezane s pretiravanji predvsem glede njihove iskanosti in cene, a nedvomno velja, da so gomoljike najbolj cenjene med vsemi užitnimi gobami. To pripisujemo njihovemu svojevrstnemu in privlačnemu vonju in okusu, nekateri pa tudi verovanju v njihovo čudežno delovanje. Užitnim vrstam gomoljik pogovorno pravimo tudi tartufi, kar je poslovenjeno italijansko ime za gomoljike (Piltaver in Vrščaj, 2013). Pod izrazom tržne gomoljike uvrščamo tiste vrste, ki jih tradicionalno tržimo za prehrano. Iskanje gomoljik je učinkovito le z izurjenimi živalmi (slika 2) in zahteva veliko časa in znanja in zato so v primerjavi z vrstami nadzemnih gliv slabše poznane (Piltaver in Ratoša, 2006). Zaradi skromnega števila naključnih najdb podzemne glive zmotno veljajo za redke (Breitenbach in Kränzlin, 1984), sicer pa so njihova naravna rastišča razširjena preko celotnega območja zmernega podnebnega pasu, njihova pogostnost in pestrost pa je večja $\mathrm{v}$ predelih $\mathrm{s}$ toplejšim podnebjem.

Tradicija nabiranja in uporabe gomoljik v Sloveniji je izpričana v Scopolijevi Kranjski flori iz leta $1772 \mathrm{~s}$ kratkim opisom črne gomoljike, načinom njenega nabiranja in trženja. Do danes se je ohranila na območju Slovenske Istre. V Sloveniji rastejo vse evropske vrste tržnih gomoljik. Njihova naravna rastišča niso tako bogata, da bi jih lahko v večjem obsegu izkoriščali za nabiranje. Razširjena so povsod tam, kjer prevladujejo ustrezni pogoji za rast gomoljik, ki pa se od vrste do vrste razlikujejo. Značilno pa je, da se velikokrat pojavljajo na zaraščajočih in opuščenih kmetijskih območjih, še posebej ob meji z gozdom, kjer je tudi največji potencial za njihovo gojenje. Zato se odpirajo možnosti uvajanja gomoljikarstva kot dopolnilne dejavnosti na kmetijah. $\mathrm{V}$ ta namen je potrebno poiskati in oceniti morebitna rastišča.

V CRP projektu smo razvili prostorski model za opredeljevanje potencialnih rastišč poletne gomoljike, Tuber aestivum Chatin (Bergant in sod., 2013). Rezultat modela je geoinformacijski sloj prostorske ločljivosti $12,5 \times 12,5 \mathrm{~m}$ in iz nje izvedena karta ocenjene potencialne primernosti za rast ali gojenje poletne gomoljike (slika 3). Primernost za rast ali gojenje poletne gomoljike je izražena $v$ indeksu primernosti, ki ima zalogo vrednosti med 0 in 100 . Večji kot je indeks primernosti, večji potencial ima lokacija za naravno rast poletne gomoljike. Analiza karte primernosti rastišč poletne gomoljike pokaže, da je $73 \%$ ozemlja Slovenije docela neprimernih, $27 \%$ pa potencialno primernih. Od primernih je na $44 \%$ površin indeks primernosti ocenjen na več kot 80 (slika 4).
Iz karte ugotavljamo, da so v Sloveniji neprimerna za rast poletne gomoljike območja Subpanonskih ravnin in gričevij. Poleg nje tudi vsa območja z gorskim podnebjem oz. območja Alp in Visokih dinarsko kraških planot in hribovij (Snežnik, Javorniki, Hrušica, Nanos, Trnovski gozd, Velika gora, Goteniška gora) ter nekatera območja predalpskega sveta. Kot neprimerna, izstopajo tudi območja velikih kotlin in ravnin izven severovzhodne Slovenije (Ljubljanska kotlina, Novomeška kotlina, Krška kotlina, Spodnja Savinjska dolina s Celjsko kotlino). Kot neprimerno območje izstopajo tudi Brkini.

Med potencialno primerna lahko štejemo vsa ostala območja Slovenije. Tu je razdrobljenost večja. V grobem lahko rečemo, da so med primernimi območji manj primerna območja Predalpskega hribovja in Predalpskih dolin in kotlin. Najprimernejša območja so zelo pogosta v Submediteranskih pokrajinah, zlasti na Kraških ravnikih in podoljih, kot je Kras, na območju Dinarskokraških podolij in ravnikov ter južni del Posavskega hribovja. Manjša zgostitev zelo primernih potencialnih površin je vidna na območju Kozjanskega in zahodnega dela Bele krajine.

Rezultate prostorskega modela potencialnih rastišč poletne gomoljike smo preverili na 21 lokacijah. Validacija modela je pokazala srednje dobro napovedno moč prostorskega modela in zato ga ocenjujemo kot perspektivnega posebej $\mathrm{v}$ kombinaciji z natančnejšimi vhodnimi podatki. Model je že $\mathrm{v}$ tej fazi primeren za podporo pri iskanju naravnih rastišč poletne gomoljike, tj. za primarno podporo pri razvoju gomoljikarstva $\mathrm{v}$ Sloveniji - načrtnem gojenje gomoljik v nasadih.

Za uspešen razvoj gomoljikarstva kot dodatne dejavnosti je potrebno ugotoviti potenciale izbranih zemljišč (tla, mikroklima, primerna zemljišča) in zagotoviti vzgojo mikoriziranih sadik na osnovi domačega semenskega materiala, mikoriziranega $z$ avtohtonimi vrstami gomoljik. Dolgoletne tuje izkušnje namreč kažejo, da je eden od bistvenih pogojev za zagotovitev bodoče donosnosti nasada gomoljik uporaba avtohtonih vrst drevja in grmovja, ki so inokulirane z lokalnimi gomoljikami. To pa je mogoče doseči samo z razvojem domačih drevesnic $\mathrm{z}$ zagotovljeno sledljivostjo izvora uporabljenega genetskega materiala gostiteljev in gomoljik.

Pri vzpostavljanju gomoljkarstva kot dodatne dejavnosti smo soočeni $\mathrm{z}$ nekaterimi nevarnostmi. Namreč, nakup mikoriziranih sadik iz tujih drevesnic, še posebej od cenejših in nepreverjenih ponudnikov, lahko ogrozi uspeh bodočega nasada in širše, predstavlja vnos tujerodnih vrst. Testiranje in optimizacija talnih dejavnikov, lastne drevesnice, lokalni sevi gomoljik, ter dosleden preizkus in prilagoditev tehnologij gojenja gomoljik lokalnim razmeram sta nujen temelj uspešnega razvoja dejavnosti in prenosa znanja $v$ 
prakso. Uspešno uvajanje novih dejavnosti temelji na primerih dobrih praks, zato so učno demonstracijski centri nujni za učinkovit prenos znanj in tehnologij v gospodarsko rabo. To posebej velja za razvoj gomoljikarstva kot nove perspektivne panoge $\mathrm{v}$ slovenskem kmetijsko-gozdarskem prostoru.

Vsekakor je nujno opraviti temeljito analizo potencialov Slovenije za razvoj gomoljikarstva (trufikulture), prilagoditi oziroma dopolniti obstoječe normative, proučiti in prilagoditi stare tradicije drugod in skozi kmetijske razvojne programe podpreti program gomoljikarstva. Tradicijo nabiranja in uživanja belih in črnih gomoljik v Slovenski Istri bi bilo smiselno in predvsem na osnovi strokovnega in znanstvenega dela vzgoje gomoljik v nasadih razširiti tudi $\mathrm{v}$ tista slovenska območja, ki izkazujejo naravne pogoje za rast gomoljik.

Uspešno uvajanje gomoljikarstva v Sloveniji lahko strnemo v pet bistvenih aktivnosti:

- raziskava naravnih rastišč tržnih vrst gomoljik;

- analiza naravnih in ekonomskih potencialov za gojenje gomoljik (trufikulturo) v Sloveniji;

- vzpostavitev lastnih drevesnic in vzgoja mikoriziranih sadik z uporabo avtohtonega genetskega materiala;

- razvoj modela gojenja z vključitvijo trufikulture kot samostojne tržne dejavnosti;

- promocija in vključitev ponudbe gojenih gomoljik v okvir lokalne turistične in kulinarične ponudbe.

\section{Kontaktni naslovi}

- za vse informacije glede gomoljikarstva v Sloveniji se obrnite na Andreja Piltaverja, anpiltaver@gmail.com;

- za vse informacije glede modela se obrnite na Janeza Berganta, jani.bergant@kis.si;

- za informacije glede projekta Možnosti in omejitve pri nabiranju gob v gozdovih in razvoj gomoljikarstva v Sloveniji se obrnite na Dušana Jurca, dusan.jurc@gozdis.si;

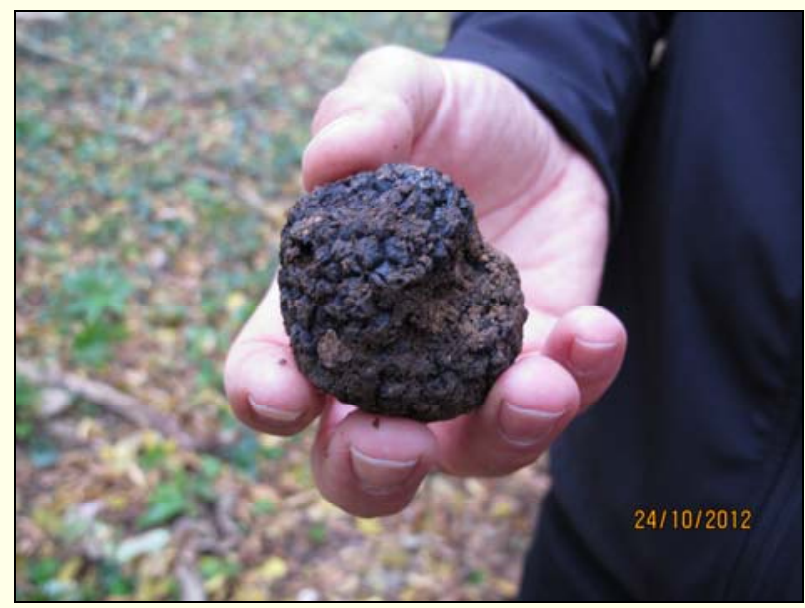

Slika 1: Poletna gomoljika, Tuber aestivum (foto: J. Bergant)
- za informacije glede sklopa D in testiranja talnih dejavnikov se obrnite na Boruta Vrščaja, borut.vrscaj@kis.si.

\section{Zahvala}

Karta potencialnih rastišč poletne gomoljike je rezultat projekta CRP V4-1145 Možnosti in omejitve pri nabiranju gob $\mathrm{v}$ gozdovih in razvoj gomoljikarstva $\mathrm{v}$ Sloveniji, sklop D: Modeliranje talnih in okoljskih parametrov kot osnova za presojo naravnih danosti za gojenje gomoljik na zaraščajočih oz. manj kakovostnih kmetijskih zemljiščih Slovenije. Projekt sta sofinancirali Ministrstvo za kmetijstvo in okolje ter Javna agencija za raziskovalno dejavnost Republike Slovenije.

\section{Viri}

Bergant J., Vrščaj B., Piltaver A., Ogris. N., Šinkovec M. 2013. Možnosti in omejitve pri nabiranju gob v gozdovih in razvoj gomoljikarstva v Sloveniji: projekt CRP V4-1145. Sklop D, Modeliranje talnih in okoljskih parametrov kot osnova za presojo naravnih danosti za gojenje gomoljik na zaraščajočih oz. manj kakovostnih kmetijskih zemljiščih Slovenij: končno poročilo. Ljubljana, Kmetijski inštitut Slovenije, KIS - Poročila o raziskovalnih nalogah, 374: 72 str.

Breitenbach J., Kränzlin F. 1984. Pilze der Schweiz, Band 1. - Mykologia. Luzern.

Piltaver A., Ratoša I. 2006. Prispevek k poznavanju podzemnih gliv v Sloveniji. Gozdarski vestnik 64: 303-312, 329-330

Piltaver A., Ratoša I. 2008. Hypogeous fungi from Slovenia, Riassunto dei $3^{\circ}$ Congresso Internationale di Spoleto sul Tartufo, 25.28. 11. 2008, str. 43.

Piltaver A., Vrščaj B. 2013. O gomoljikah - Možnosti gomoljikarstva v Sloveniji. Kmečki glas, 16. 10. 2013

1Kmetijski inštitut Slovenije, Hacquetova ulica 17, 1000 Ljubljana; 2Inštitut za sistematiko višjih gliv, Zofke Kvedrove ulica 24, 1000 Ljubljana; ${ }^{3}$ Gozdarski inštitut Slovenije, Večna pot 2, 1000 Ljubljana *jani.bergant@kis.si

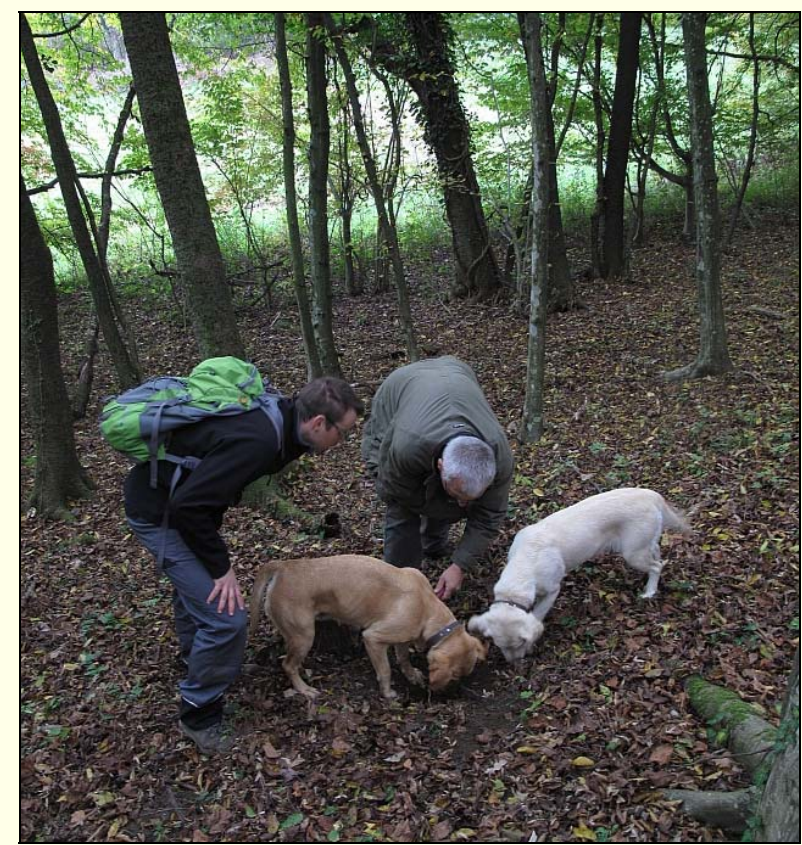

Slika 2: Danes pri iskanju gomoljik uporabljamo predvsem izurjene pse (foto: M. Šinkovec) 


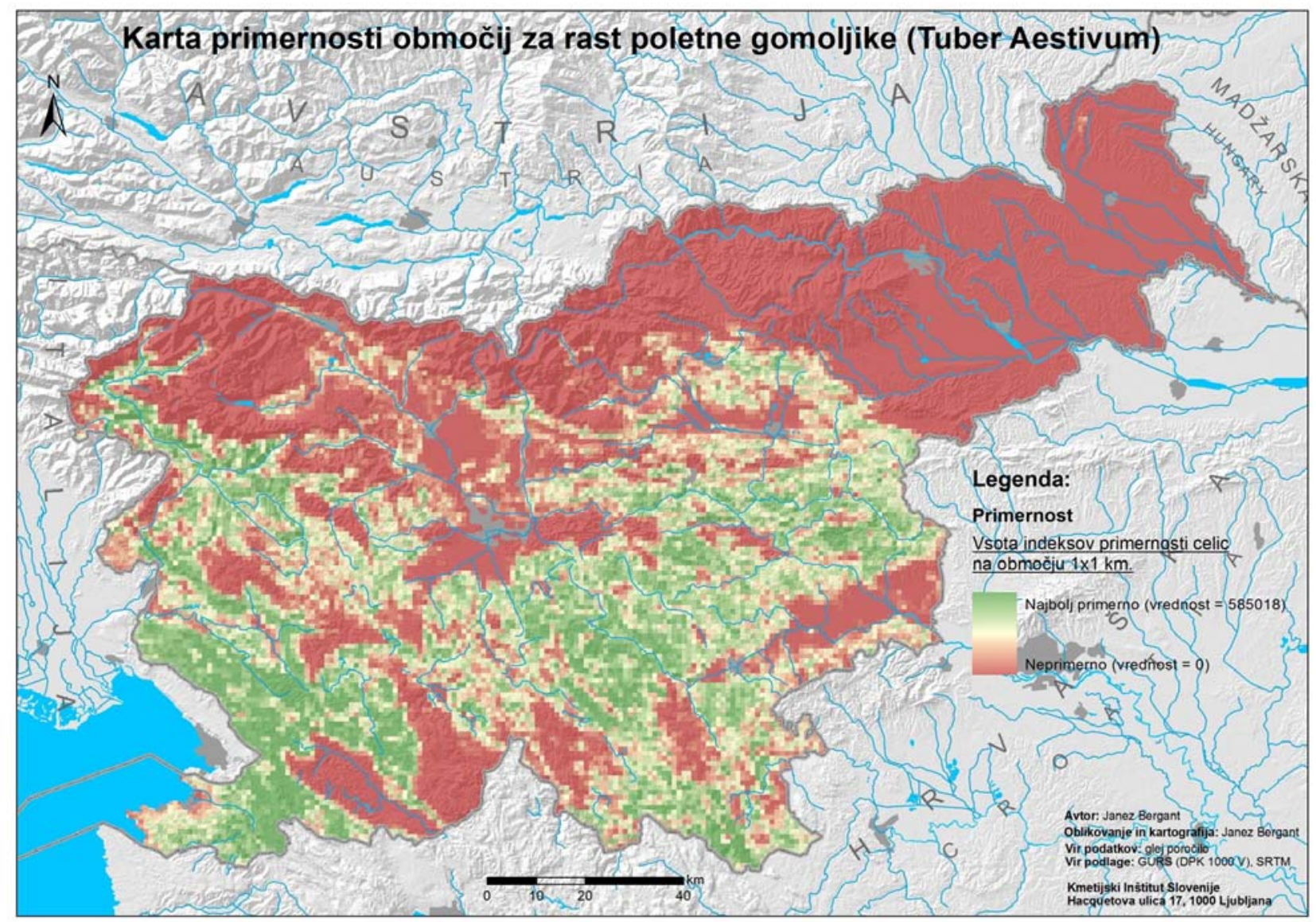

Slika 3: Karta primernosti za rast poletne gomoljike (Bergant in sod. 2013)

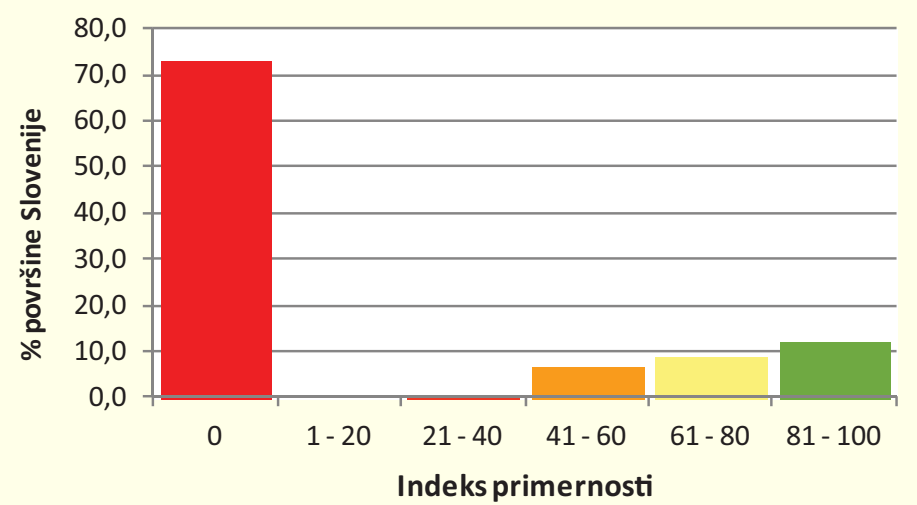

Slika 4: Odstotek površin Slovenije po razredih primernosti za rast poletne gomoljike (Bergant in sod. 2013) 